\title{
Disposition and Metabolic Fate of Clentiazem in Rats and Dogs
}

\author{
Susumu Nakamura, ${ }^{* a}$ Y Yoichi Sugawara, ${ }^{a}$ Takeshi Fukushima,${ }^{a}$ Yutaka Ito, ${ }^{b}$ \\ Motoaki OHASHI, ${ }^{c}$ and Osasi TAKAITI ${ }^{a}$ \\ Research Laboratory of Drug Metabolism, ${ }^{a}$ Pharmacological Research Laboratory, ${ }^{b}$ and Biological Research Laboratory, \\ Tanabe Seiyaku Co., Ltd., 2-2-50, Kawagishi, Toda, Saitama 335, Japan. Received September 3, 1992
}

The plasma concentrations and time courses of radioactivity and unchanged drug, the excretion of radioactivity into urine and feces, and the proportion of metabolites in plasma and urine were studied after oral administration of $\left[{ }^{14} \mathrm{C}\right]$ clentiazem to male and female rats and dogs.

Apparent sex-related differences were found in the disposition and metabolism of clentiazem in rats. The plasma levels of radioactivity and acidic metabolites were higher in males than in females. The plasma levels of unchanged drug, on the other hand, were about the same in both sexes.

Higher conversion of clentiazem to its acidic metabolites in the liver of male rats and higher excretion of the acidic metabolites in the urine of female rats, presumably due to sex-related differences in cytochrome $P-450$ and renal clearance, respectively, seem to explain these differences in the disposition of clentiazem in male and female rats.

No suggestion of a similar sex difference was found in dogs. The plasma concentrations and time courses of radioactivity and unchanged drug in male dogs were similar to those in female dogs, and the excretion of radioactivity in both sexes was also similar. The main plasma metabolite in male and female dogs was $O$-demethyl clentiazem (MB7).

A species difference between rat and dog was suggested, since the major metabolic pathways were different and no sex difference was found in dogs.

Keywords clentiazem; metabolism; rat; dog; sex difference

\section{Introduction}

$(+)-(2 S, 3 S)-3$-Acetoxy-8-chloro-5-[2-(dimethylamino)ethyl]-2,3-dihydro-2-(4-methoxyphenyl)-1,5-benzothiazepin-4(5H)-one maleate (clentiazem, TA-3090) is a new $\mathrm{Ca}^{2+}$-channel blocking agent developed by Tanabe Seiyaku Co., Ltd. ${ }^{1)}$ The disposition and metabolism of diltiazem, which has been widely used for the treatment of various cardiac disorders ${ }^{2)}$ and has a similar structure to clentiazem, were studied in rats, dogs and humans. ${ }^{3-8)}$ The biotransformation of clentiazem in male rats has been previously reported $^{9,10)}$ and it was found that its metabolic profile was similar to that of diltiazem.

We studied here the levels and time courses of radioactivity and unchanged drug in plasma, urinary and fecal excretion of radioactivity and the proportions of metabolites in plasma, urine and bile of male and female rats and dogs.

\section{Materials and Methods}

Chemicals The structure and position of the label in $\left[{ }^{14} \mathrm{C}\right]$ clentiazem is shown in Fig. 1. $\left[{ }^{14} \mathrm{C}\right]$ Clentiazem was synthesized from $\left[{ }^{14} \mathrm{C}\right.$-ethyl]dimethylaminoethyl chloride hydrochloride in the Research Laboratory of Drug Metabolism of the Tanabe Seiyaku Co., Ltd. or Amersham International (Buckinghamshire, U.K.) according to the synthetic route previously reported. ${ }^{10)}$ The specific radioactivity of $\left[{ }^{14} \mathrm{C}\right]$ clentiazem was $0.5,1.35$ and $1.84 \mathrm{MBq} / \mathrm{mg}$ and the radiochemical purity, determined by TLC, was greater than $98 \%$. The labeled compound was diluted with unlabeled clentiazem before use according to experimental conditions.

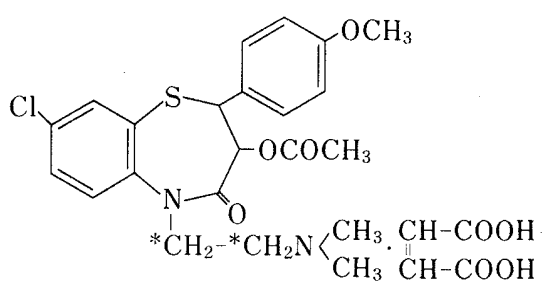

Fig. 1. Chemical Structure and Labeled Position of $\left[{ }^{14} \mathrm{C}\right]$ Clentiazem *: Labeled position of ${ }^{14} \mathrm{C}$.
Animals Male ( 7 weeks old) and female ( 7 and 10 weeks old) Sprague-Dawley rats were purchased from Charles River Japan (Kanagawa, Japan). Male and female Beagle dogs (12 months old) were purchased from Yoshiki Farm (Gifu, Japan). Animals were fasted overnight before dosing with $\left[{ }^{14} \mathrm{C}\right]$ clentiazem, but had free access to water.

Dosage $\left[{ }^{14} \mathrm{C}\right]$ Clentiazem was dissolved in water to give a concentration of $6 \mathrm{mg} / \mathrm{ml}$ for dosing to rats or $2 \mathrm{mg} / \mathrm{ml}$ for dosing to dogs. An appropriate amount of the solution was administered by stomach intubation, at a dose of $30 \mathrm{mg} / \mathrm{kg}$ to rats and $2 \mathrm{mg} / \mathrm{kg}$ to dogs.

Plasma Levels of Radioactivity and Unchanged Drug Following oral administration of $\left[{ }^{14} \mathrm{C}\right]$ clentiazem to male and female rats and dogs, blood samples were taken form the jugular vein of rats and from the cephalic veins of dogs at scheduled time intervals. Plasma was collected by centrifugation at $4^{\circ} \mathrm{C}$ for $5 \mathrm{~min}(4000 \times g$, Tomy RL-101, Tokyo, Japan). The radioactivity in the plasma was measured using a liquid scintillation counter (Tri-Carb 460CD, Packard, IL, U.S.A.) after solubilization with Soluene 350 (Packard) and addition of scintillation cocktail (Hionic fluor, Packard). Concentrations of the unchanged drug in plasma were measured using GC-MS as described below.

GC-MS Analysis For the determination of plasma levels of the unchanged drug, a Hitachi M-80A gas chromatograph/mass spectrometer (Tokyo, Japan), equipped with a Hitachi M-003 data processing system, was used in the negative ion chemical ionization mode.

Urinary and Fecal Excretion Following oral administration of $\left[{ }^{14} \mathrm{C}\right]$ clentiazem to male and female rats and dogs, urine and feces were collected at scheduled time intervals. The urine samples were diluted with water and aliquots were used to measure radioactivity after addition of a toluene-Triton X-100 based scintillation cocktail 2,5-diphenyloxazole (DPO) $12 \mathrm{~g}$, dimethyl 1,4-bis-2-(5-phenyloxazole)benzene $3 \mathrm{~g}$, Triton X-100 11 , toluene 21 ). Feces samples were homogenized with water. Aliquots of the homogenate of rat feces were combusted using an automatic combustion apparatus (Aloka ASC-113, Tokyo, Japan) and the ${ }^{14} \mathrm{CO}_{2}$ was absorbed by a mixture of ethanolamine and methanol and then was measured in a liquid scintillation counter. Aliquots of the homogenate of dog feces were solubilized with Soluene 350 , and then the radioactivity was measured using the liquid scintillation counter, after addition of scintillation cocktail (Hionic fluor, Packard).

Biliary Excretion Bile was collected from the cannulated bile duct of male and female rats at scheduled time intervals after oral administration of $\left[{ }^{14} \mathrm{C}\right]$ clentiazem. The bile was diluted to a fixed volume with water. The radioactivity of aliquots was measured with the liquid scintillation counter after addition of a toluene-Triton X-100 based scintillation cocktail.

Separation and Determination of Metabolites The collected plasma and urine samples were adjusted to $\mathrm{pH} 2$ with $1 \mathrm{~N} \mathrm{HCl}$ and extracted twice 
<smiles>COc1ccc(C2Sc3cc(Cl)ccc3N(CC(=O)O)C(=O)C2OC(C)=O)cc1</smiles><smiles>COc1ccc(C2Sc3cc(Cl)ccc3N(CC(=O)O)C(=O)C2O)cc1</smiles><smiles>COc1ccc(C2Sc3cc(Cl)ccc3N(CCCN(C)C)C(=O)C2O)cc1</smiles><smiles>[CH]NCCN1C(=O)C(OC(C)=O)C(c2ccc(OC)cc2)Sc2cc(Cl)ccc21</smiles><smiles>CNCCN1C(=O)C(OC(C)=O)C(c2ccc(O)cc2)Sc2cc(Cl)ccc21</smiles><smiles>CC(=O)OC1C(=O)N(CC(=O)O)c2ccc(Cl)cc2SC1c1ccc(O)cc1</smiles><smiles>CCN1C(=O)C(O)C(c2ccc(O)cc2)Sc2cc(Cl)ccc21</smiles><smiles>CNCCCN1C(=O)C(O)C(c2ccc(OC)cc2)Sc2cc(Cl)ccc21</smiles><smiles>CNCCN1C(=O)C(O)C(c2ccc(O)cc2)Sc2cc(Cl)ccc21</smiles>

Fig. 2. Chemical Structures of Acidic Metabolites (MA1-4) and Basic Metabolites (MB1-7)

(rats) or three times (dogs) with tert-butyl methyl ether ( $t$-BME) to obtain the acidic and neutral metabolite fraction. Subsequently, the aqueous phases were adjusted to $\mathrm{pH} 8$ with $1 \mathrm{~N}$ ammonia and then extracted twice with $t$-BME to obtain the basic metabolite fraction. Aliquots of these $t$-BME extracts and the residual aqueous phases were monitored for radioactivity to determine the relative proportions of lipid-soluble acidic, neutral, basic and aqueous metabolite fraction in the samples. The $t$-BME extracts were evaporated to dryness under reduced pressure. The residues were dissolved in a mixture of dioxane and water $(1: 1, \mathrm{v} / \mathrm{v})$. After addition of authentic samples of MAl-4 (Fig. 2) to the acidic and neutral metabolite fraction, or clentiazem and $\mathrm{MBL}-7$ (Fig. 2) to the basic metabolite fraction, the resulting solutions were subjected to HPLC and detection performed by means of a radioanalyzer (Aloka, ACM-550).

The peaks, MAl-4, or clentiazem and $\mathrm{MBI}-7$, in the radiochromatograms of the samples were assigned by comparing retention times with those of the UV peaks of the authentic compounds.

Preparation of Liver Microsomes Liver microsome preparations were obtained from mature male ( 7 weeks old) or female ( 7 or 10 weeks old) rats. Animals were killed and their livers removed. After homogenization of the liver in 3 volumes of cold $1.15 \% \mathrm{KCl}$ solution with a Potter-Elvehjem homogenizer, the homogenate was centrifuged at $1000 \times \boldsymbol{g}$ for $10 \mathrm{~min}$. The supernatants were centrifuged at $9000 \times g$ for $10 \mathrm{~min}$. The crude microsomes were separated from the supernatant by centrifugation at $105000 \times g$ for $70 \mathrm{~min}$. After the separated crude microsomes were dispersed in $0.05 \mathrm{M} \mathrm{Na}-\mathrm{K}$ phosphate buffer $(\mathrm{pH}$ 7.4) using a Potter-Elvehjem homogenizer, the suspension was centrifuged again at $105000 \times g$ for $70 \mathrm{~min}$. The separated microsomes were suspended in $0.05 \mathrm{M} \mathrm{Na}-\mathrm{K}$ phosphate buffer $(\mathrm{pH} 7.4)$ and kept at $-80^{\circ} \mathrm{C}$. All operations during the procedure were carried out at $4^{\circ} \mathrm{C}$.

In Vitro Metabolism Incubations were carried out aerobically in conical flasks at $37^{\circ} \mathrm{C}$ for $60 \mathrm{~min}$. Each flask contained the liver microsome suspension (final concentration, male: $0.72 \mathrm{mg} \cdot \operatorname{protein} / \mathrm{ml}$, female ( 7 weeks old): $0.46 \mathrm{mg} \cdot$ protein $/ \mathrm{ml}$, female $(10$ weeks old): $0.56 \mathrm{mg} \cdot \operatorname{protein} / \mathrm{ml}$ ), glucose 6-phosphate (final concentration; $2.9 \mathrm{~mm}$ ), glucose 6-phosphate dehydrogenase (10 units), NADP (final concentration; $1.1 \mathrm{~mm}$ ), $\mathrm{MgCl}_{2}$. $6 \mathrm{H}_{2} \mathrm{O}$ (final concentration; $14.3 \mathrm{~mm}$ ) and $0.05 \mathrm{M} \mathrm{Na}-\mathrm{K}$ phosphate buffer (pH 7.4). Reactions were started by addition of $\left[{ }^{14} \mathrm{C}\right]$ clentiazem (final concentration; $10^{-5} \mathrm{M}$ ) and terminated by addition of $1 \mathrm{ml} 1 \mathrm{~N} \mathrm{HCl}$.

The reaction mixtures were extracted with $t$-BME to separate the acidic and neutral, and basic metabolite fractions as described above. The extracts were analyzed to determine metabolites by HPLC using a radiodetector.

HPLC A Hitachi 655-15 high performance liquid chromatograph and
Nova Pak C18 column ( $8 \mathrm{~mm}$ i.d. $\times 10 \mathrm{~cm}, 5 \mu \mathrm{m}$, Waters, Division of Millipore Co., MA, U.S.A.) were used for the separation of each metabolite. Radioactivity was monitored with a radioanalyzer (Aloka, RLC-551).

The mobile phases used for analysis of the basic metabolites were; A) acetonitrile-tetrahydrofuran $(7: 3, \mathrm{v} / \mathrm{v})$ and $\mathrm{B}) 0.1 \mathrm{M}$ sodium phosphate buffer pH 7.9 (adjusted with triethylamine). For the analysis of the acidic metabolites; A) acetonitrile-tetrahydrofuran $(7: 3, \mathrm{v} / \mathrm{v})$ and $\mathrm{B}) 0.1 \mathrm{~m}$ sodium phosphate buffer, pH 2.2 (adjusted with phosphoric acid) were used. A combination of isocratic and gradient elution was used, i.e. the proportions of solvent A: B were $25: 75,25: 75,50: 50$ and $50: 50$ at $0,1,25$ and $30 \mathrm{~min}$ after sample injection.

\section{Results}

Plasma Concentration of Radioactivity and the Unchanged Drug 1) Rat Figure 3 shows the time courses of the concentrations of radioactivity and unchanged drug in the plasma of male and female rats after oral administration of $\left[{ }^{14} \mathrm{C}\right]$ clentiazem. In male rats, the plasma concentration of radioactivity rose rapidly up to $30 \mathrm{~min}$ after administration. Thereafter, the increase of radioactivity became slower, and the maximum concentration of radioactivity was observed $6 \mathrm{~h}$ after dosing. A similar time course was also observed in the plasma concentrations of radioactivity in female rats, but the levels in the females were about half that of the males.

The maximum concentrations of unchanged drug in plasma were observed $1 \mathrm{~h}$ after administration, $0.45 \mu \mathrm{g} / \mathrm{ml}$ in males and $0.31 \mu \mathrm{g} / \mathrm{ml}$ in females. The difference between these two values was not statistically significant. The values of the pharmacokinetic parameters $\left(C_{\max }, T_{\max }, t_{1 / 2}\right.$ and $A U C_{\text {inf }}$ ) calculated by application of a one-compartment model showed no significant difference between males and females as shown in Table I.

2) Dog Figure 4 shows the time courses of the concentrations of radioactivity and unchanged drug in the plasma of male and female dogs after oral administration 


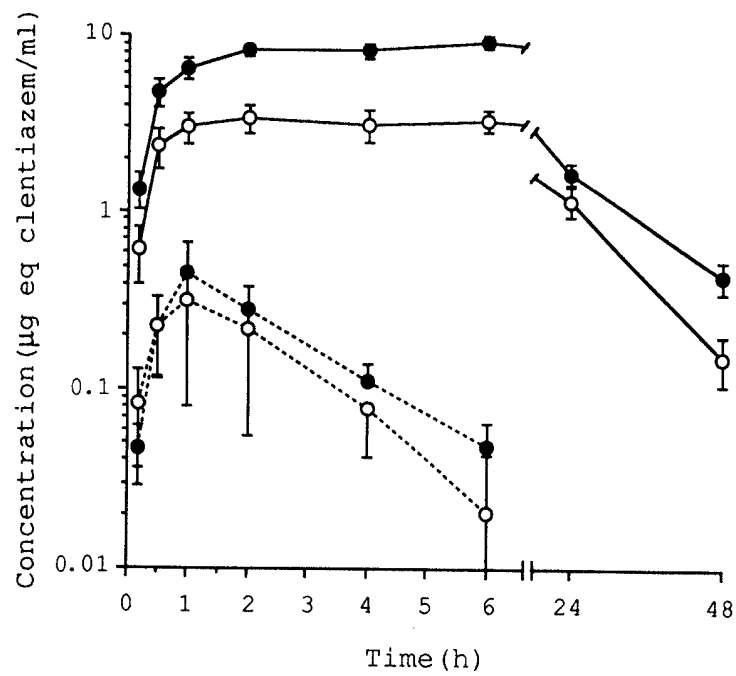

Fig. 3. Plasma Levels of Radioactivity and Unchanged Drug after Oral Administration of $\left[{ }^{14} \mathrm{C}\right]$ Clentiazem at a Dose of $30 \mathrm{mg} / \mathrm{kg}$ to Male and Female Rats

Each point represents mean \pm S.D. of 6 animals. - - - male radioactivity; $-\mathrm{O}-$ female radioactivity; ...-...-, male unchanged drug; ... -..., female unchanged drug.

TABle I. Pharmacokinetic Parameters of Clentiazem in Plasma of Rats and Dogs

\begin{tabular}{clcccc}
\hline \hline Animal & Sex & $\begin{array}{c}T_{\max } \\
(\mathrm{h})\end{array}$ & $\begin{array}{c}C_{\max } \\
(\mu \mathrm{g})\end{array}$ & $\begin{array}{c}t_{1 / 2} \\
(\mathrm{~h})\end{array}$ & $\begin{array}{c}A U C_{\text {inf }} \\
\left(\mu \mathrm{g} \cdot \mathrm{ml}^{-1} \cdot \mathrm{h}\right)\end{array}$ \\
\hline \multirow{2}{*}{ Rat } & Male & $1.29 \pm 0.30$ & $0.366 \pm 0.158$ & $0.97 \pm 0.21$ & $1.22 \pm 0.42$ \\
& Female & $0.91 \pm 0.29$ & $0.289 \pm 0.182$ & $1.25 \pm 0.57$ & $0.92 \pm 0.59$ \\
Dog & Male & $1.63 \pm 0.72$ & $0.040 \pm 0.014$ & $2.63 \pm 0.72$ & $0.221 \pm 0.026$ \\
& Female & $0.69 \pm 0.06$ & $0.055 \pm 0.017$ & $1.95 \pm 0.73$ & $0.211 \pm 0.122$
\end{tabular}

Each value represents the mean \pm S.D. (rat, $n=5$; $\cdot$ dog, $n=3$ ).

of $\left[{ }^{14} \mathrm{C}\right]$ clentiazem. The maximum concentrations of both radioactivity and unchanged drug were observed $1 \mathrm{~h}$ after dosing in male dogs, while in females these were attained $30 \mathrm{~min}$ after dosing. However, the time courses of these plasma concentrations were nearly equal in both sexes.

The $C_{\max }$ value was slightly higher in female dogs than that in males as shown in Table I. The $T_{\max }$ and $t_{1 / 2}$ values were slightly longer in males dogs than in females. However, no significant sex difference in these parameters was found. The value of $A U C_{\text {inf }}$ was about the same in both sexes.

Plasma Metabolites 1) Rat Table II shows the percentages and concentrations of radioactivity in the acidic and neutral, basic and aqueous metabolite fractions in the plasma obtained at scheduled time intervals after oral administration of $\left[{ }^{14} \mathrm{C}\right]$ clentiazem to male and female rats. In the male rats, the percentages of the acidic and neutral metabolite fraction were extremely high in comparison with the basic and aqueous metabolite fractions and this increased with time; they were $66.5,73.1,73.9$ and $80.8 \%$ of plasma radioactivity at $30 \mathrm{~min}, 1,2$ and $6 \mathrm{~h}$ after administration, respectively. In female rats they also increased, but the values were low in comparison with those in males being $31.0,41.9,42.1$ and $52.4 \%$ of plasma radioactivity at $30 \mathrm{~min}, 1,2$ and $6 \mathrm{~h}$ after administration, respectively. In contrast, the percentages of radioactivity in the basic metabolite fraction were higher in female rats than in males. In female rats they accounted for $63.1 \%$ of plasma

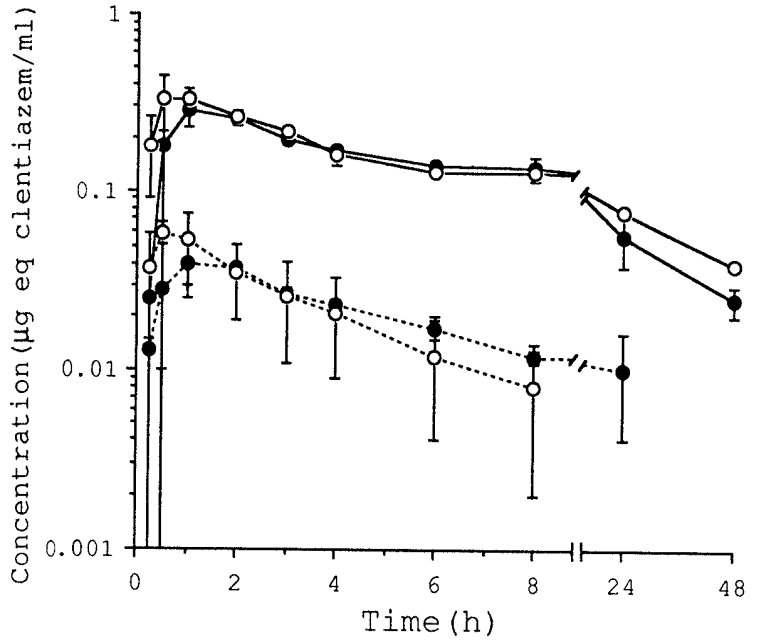

Fig. 4. Plasma Levels of Radioactivity and Unchanged Drug after Oral Administration of $\left[{ }^{14} \mathrm{C}\right]$ Clentiazem at a Dose of $2 \mathrm{mg} / \mathrm{kg}$ to Male and Female Dogs

Vertical bars represent S.D. of the mean $(n=3)$. - - - male radioactivity; $-\mathrm{O}-$, female radioactivity; --- ---, male unchanged drug; --. --., female unchanged drug.

TABLE II. Proportion and Concentration of Radioactivity in Acidic and Neutral, Basic and Aqueous Metabolite Fractions in Plasma after Oral Administration of $\left[{ }^{14} \mathrm{C}\right]$ Clentiazem to Male and Female Rats

\begin{tabular}{|c|c|c|c|c|c|c|}
\hline \multirow{3}{*}{$\begin{array}{l}\text { Time } \\
\text { (h) }\end{array}$} & \multicolumn{6}{|c|}{$\%$ of radioactivity in plasma } \\
\hline & \multicolumn{3}{|c|}{ Male } & \multicolumn{3}{|c|}{ Female } \\
\hline & $\begin{array}{c}\text { Acidic and } \\
\text { neutral }\end{array}$ & Basic & Aqueous & $\begin{array}{c}\text { Acidic and } \\
\text { neutral }\end{array}$ & Basic & Aqueous \\
\hline \multirow[t]{2}{*}{0.5} & 66.5 & 27.6 & 5.9 & 31.0 & 63.1 & 5.9 \\
\hline & $(2.61)$ & $(1.08)$ & $(0.23)$ & $(0.78)$ & $(1.58)$ & $(0.15)$ \\
\hline \multirow[t]{2}{*}{1} & 73.1 & 20.4 & 6.5 & 41.9 & 51.6 & 6.5 \\
\hline & $(4.02)$ & $(1.12)$ & $(0.36)$ & $(1.13)$ & $(1.39)$ & $(0.18)$ \\
\hline \multirow[t]{2}{*}{2} & 73.9 & 18.4 & 7.7 & 42.1 & 52.0 & 5.9 \\
\hline & $(4.31)$ & $(1.08)$ & $(0.45)$ & $(1.26)$ & $(1.55)$ & $(0.18)$ \\
\hline \multirow[t]{2}{*}{6} & 80.8 & 7.5 & 11.7 & 52.4 & 39.9 & 7.7 \\
\hline & $(6.16)$ & $(0.57)$ & $(0.89)$ & $(1.55)$ & $(1.18)$ & $(0.23)$ \\
\hline
\end{tabular}

Values in parentheses are expressed as the concentration of clentiazem ( $\mu \mathrm{g}$ eq clentiazem $/ \mathrm{ml}$ ). Each value was obtained using the pooled plasma of 5 animals.

radioactivity at $30 \mathrm{~min}$ and $39.9 \%$ at $6 \mathrm{~h}$ after dosing. In male rats, they accounted for $27.6 \%$ of the plasma radioactivity at $30 \mathrm{~min}$ and $7.5 \%$ at $6 \mathrm{~h}$ after dosing. The percentages of radioactivity in the aqueous metabolite fraction of both sexes were low, $6-12 \%$ of plasma radioactivity.

The concentrations of acidic and basic metabolites at 30 min, 1, 2 and $6 \mathrm{~h}$ are shown in Fig. 5. The concentration of MA2 in the acidic and neutral metabolite fraction of male rats was highest, followed by that of MA4 at every time interval. The concentrations of MA2 and MA4 increased gradually from $30 \mathrm{~min}$ to $6 \mathrm{~h}$ after dosing. On the other hand, the concentrations of MA1 and MA3 were low at every time interval, and decreased gradually from $30 \mathrm{~min}$ to $6 \mathrm{~h}$. The concentration of each acidic metabolite was lower in female rats than in males. The concentration of MA2 was highest, followed by that of MA4. The time courses of acidic metabolites in female rats were similar to those in males.

The concentration of each basic metabolite was low, the 

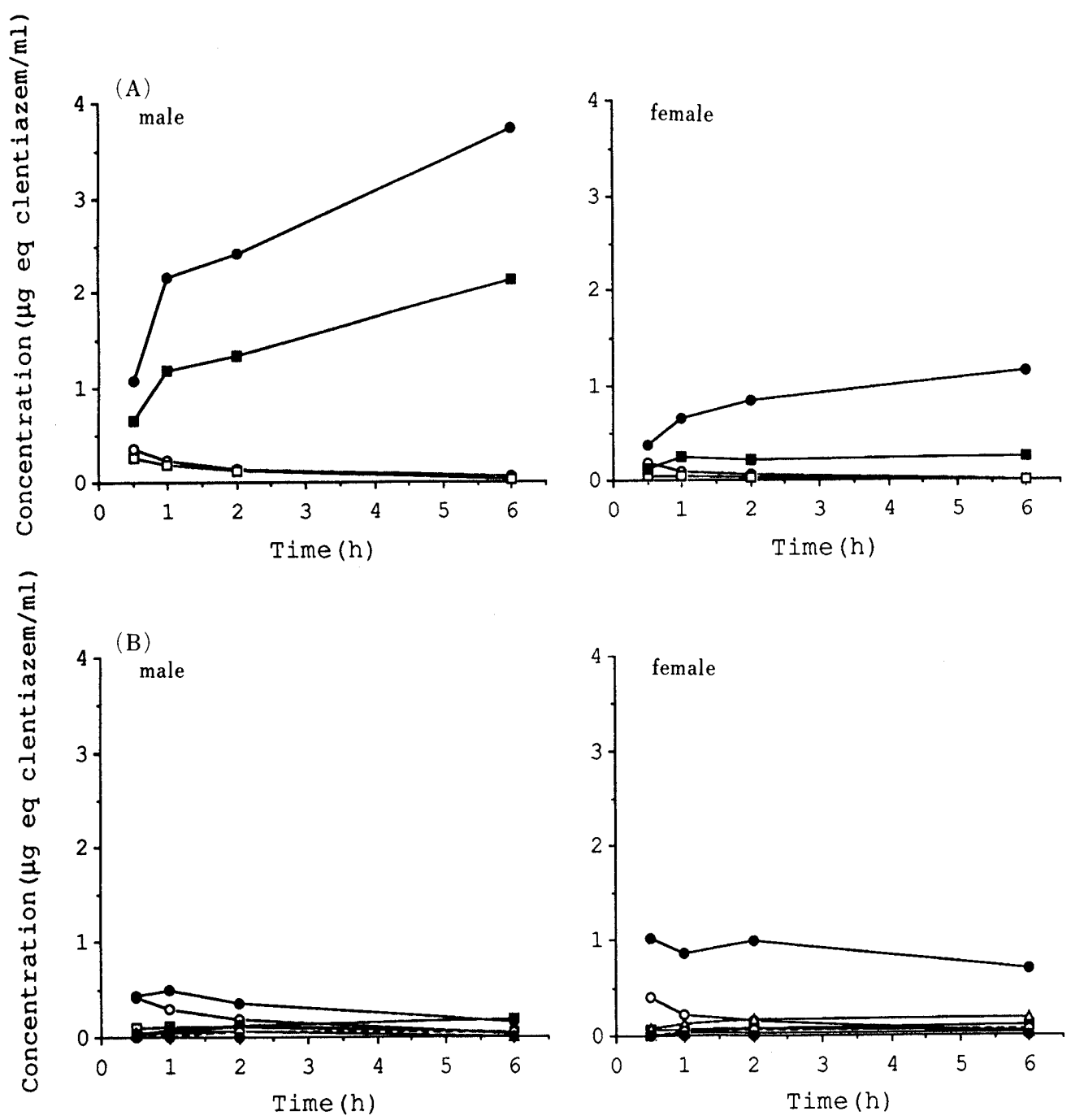

Fig. 5. Concentrations of Acidic Metabolites (A) and Unchanged Drug and Basic Metabolites (B) in the Plasma of Male and Female Rats

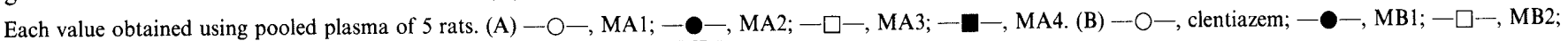
$-\mathbf{\square}-\mathrm{MB} 3 ;-\triangle-, \mathrm{MB} 4 ;-\mathbf{\Delta}-, \mathrm{MB} 5 ;--\mathrm{O}_{---}, \mathrm{MB} 6 ;---\bullet--, \mathrm{MB} 7$.

TABle III. Proportion and Concentration of Radioactivity in Acidic and Neutral, Basic and Aqueous Metabolite Fractions in Plasma after Oral Administration of $\left[{ }^{14} \mathrm{C}\right]$ Clentiazem to Male and Female Dogs

\begin{tabular}{|c|c|c|c|c|c|c|}
\hline \multirow{3}{*}{$\begin{array}{l}\text { Time } \\
\text { (h) }\end{array}$} & \multicolumn{5}{|c|}{$\%$ of radioactivity in plasma } & \\
\hline & \multicolumn{3}{|c|}{ Male } & \multicolumn{3}{|c|}{ Female } \\
\hline & $\begin{array}{l}\text { Acidic and } \\
\text { neutral }\end{array}$ & Basic & Aqueous & $\begin{array}{c}\text { Acidic and } \\
\text { neutral }\end{array}$ & Basic & Aqueous \\
\hline 0.5 & $\begin{array}{l}26.7 \\
(0.11)\end{array}$ & $\begin{array}{c}39.1 \\
(0.16)\end{array}$ & $\begin{array}{c}34.2 \\
(0.14)\end{array}$ & $\begin{array}{l}23.1 \\
(0.07)\end{array}$ & $\begin{array}{l}50.3 \\
(0.16)\end{array}$ & $\begin{array}{l}26.7 \\
(0.09)\end{array}$ \\
\hline 2 & $\begin{array}{l}21.8 \\
(0.06)\end{array}$ & $\begin{array}{l}39.9 \\
(0.11)\end{array}$ & $\begin{array}{c}38.3 \\
(0.11)\end{array}$ & $\begin{array}{l}19.3 \\
(0.05)\end{array}$ & $\begin{array}{l}49.8 \\
(0.12)\end{array}$ & $\begin{array}{l}31.0 \\
(0.08)\end{array}$ \\
\hline 6 & $\begin{array}{l}20.3 \\
(0.03)\end{array}$ & $\begin{array}{c}39.7 \\
(0.07)\end{array}$ & $\begin{array}{c}40.0 \\
(0.07)\end{array}$ & $\begin{array}{c}17.6 \\
(0.03)\end{array}$ & $\begin{array}{l}45.7 \\
(0.07)\end{array}$ & $\begin{array}{c}36.7 \\
(0.06)\end{array}$ \\
\hline 24 & $\begin{array}{c}20.9 \\
(0.02)\end{array}$ & $\begin{array}{c}29.0 \\
(0.02)\end{array}$ & $\begin{array}{c}50.1 \\
(0.04)\end{array}$ & $\begin{array}{l}13.0 \\
(0.01)\end{array}$ & $\begin{array}{c}29.6 \\
(0.02)\end{array}$ & $\begin{array}{l}57.3 \\
(0.04)\end{array}$ \\
\hline
\end{tabular}

Values in parentheses are expressed as the concentration of clentiazem $(\mu \mathrm{g}$ eq clentiazem $/ \mathrm{ml}$ ). Each value was obtained using pooled plasma of 3 animals.

concentrations of $\mathrm{MB1}$ and unchanged drug were high in the basic metabolite fraction. The concentration of MB1 in female rats was highest at every time interval, followed by that of unchanged drug up to $2 \mathrm{~h}$.
The concentration of $\mathrm{MB} 1$ in female rats was 1.7-4.7 times higher than that in males.

2) Dog The percentages and concentrations of radioactivity in the acidic and neutral, basic and aqueous metabolite fraction in the plasma after oral administration of $\left[{ }^{14} \mathrm{C}\right]$ clentiazem to male and female dogs are shown in Table III. The highest concentrations of radioactivity in the basic metabolite fraction were found up to $2 \mathrm{~h}$ after administration in the male rats, and up to $6 \mathrm{~h}$ in the females, followed by that in the aqueous metabolite fraction, while those of the acidic and neutral metabolite fraction were low. The percentages of radioactivity in the aqueous metabolite fraction reached the highest, followed by that in the basic metabolite fraction at 6 and $24 \mathrm{~h}$ after oral administration to male dogs, and at $24 \mathrm{~h}$ after oral administration to females. The concentration of radioactivity in each metabolite fraction gradually declined with time in male and female dogs.

Figure 6 shows the concentrations of acidic and basic metabolites in dog plasma. In male dogs, the concentration of MA2 was highest in the acidic and neutral metabolite fraction at every time interval. The concentrations of the acidic metabolites decreased gradually except for MA4. The concentration of MA4 was lower than those of the other 

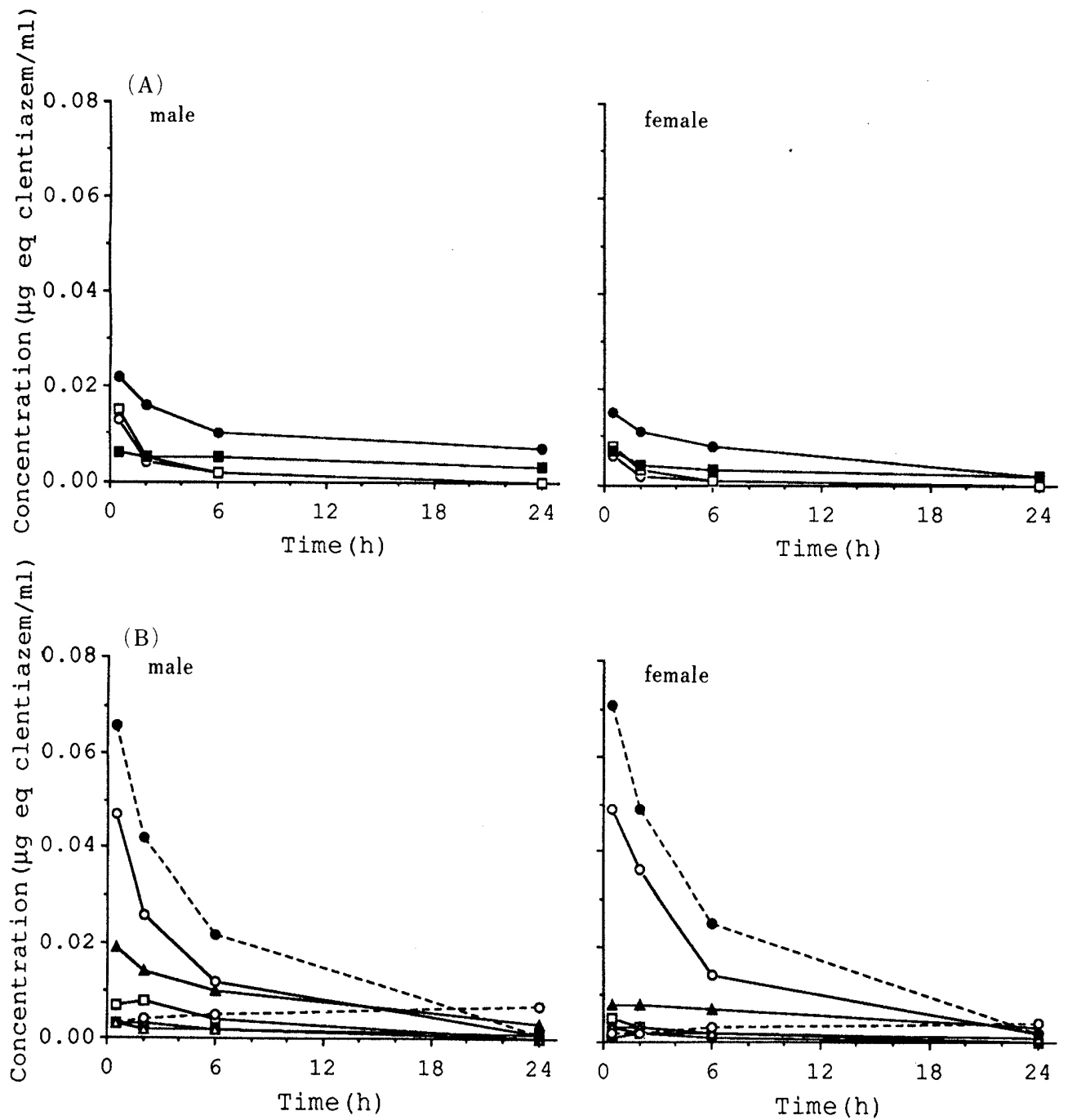

Fig. 6. Concentrations of Acidic Metabolites (A) and Unchanged Drug and Basic Metabolites (B) in the Plasma of Male and Female Dogs

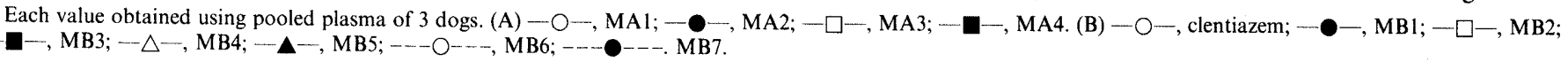

TABLE IV. Urinary and Fecal Excretion Rates after Oral Administration of $\left[{ }^{14} \mathrm{C}\right]$ Clentiazem to Male and Female Rats and Dogs

\begin{tabular}{|c|c|c|c|c|c|c|c|}
\hline \multirow{2}{*}{\multicolumn{2}{|c|}{ Animal }} & \multirow{2}{*}{ Sex } & \multicolumn{5}{|c|}{ Excretion rates ( $\%$ of dose) } \\
\hline & & & $0-3 \mathrm{~h}$ & $0-6 \mathrm{~h}$ & $0-24 \mathrm{~h}$ & $0-48 \mathrm{~h}$ & $0-72 \mathrm{~h}$ \\
\hline \multirow[t]{2}{*}{ Rat } & $\begin{array}{l}\text { Urine } \\
\text { Feces }\end{array}$ & $\begin{array}{l}\text { Male } \\
\text { Female } \\
\text { Male } \\
\text { Female }\end{array}$ & $\begin{array}{c}2.9 \pm 0.8 \\
4.1 \pm 1.5 \\
- \\
-\end{array}$ & $\begin{array}{c}6.7 \pm 0.2 \\
9.6 \pm 1.9 \\
- \\
-\end{array}$ & $\begin{array}{l}13.8 \pm 1.2 \\
29.5 \pm 2.2 \\
61.2 \pm 7.2 \\
33.0 \pm 17.7\end{array}$ & $\begin{array}{l}14.6 \pm 1.2 \\
33.6 \pm 0.5 \\
77.8 \pm 1.4 \\
57.7 \pm 9.2\end{array}$ & $\begin{array}{l}14.9 \pm 1.1 \\
34.4 \pm 0.7 \\
79.1 \pm 1.1 \\
63.1 \pm 3.3\end{array}$ \\
\hline & & & & $0-8 \mathrm{~h}$ & $0-24 \mathrm{~h}$ & $0-48 \mathrm{~h}$ & $0-72 \mathrm{~h}$ \\
\hline Dog & $\begin{array}{l}\text { Urine } \\
\text { Feces }\end{array}$ & $\begin{array}{l}\text { Male } \\
\text { Female } \\
\text { Male } \\
\text { Female }\end{array}$ & & $\begin{array}{c}2.2 \pm 1.2 \\
5.2 \pm 0.6 \\
- \\
-\end{array}$ & $\begin{array}{l}11.0 \pm 0.4 \\
11.4 \pm 0.5 \\
30.9 \pm 5.2 \\
30.2 \pm 6.8\end{array}$ & $\begin{array}{l}14.5 \pm 1.1 \\
15.3 \pm 1.0 \\
61.2 \pm 2.9 \\
50.8 \pm 6.0\end{array}$ & $\begin{array}{l}15.8 \pm 1.3 \\
16.6 \pm 1.1 \\
69.4 \pm 2.7 \\
61.6 \pm 8.9\end{array}$ \\
\hline
\end{tabular}

Each value represents the mean \pm S.D. (rat, $n=5 ; \operatorname{dog}, n=3$ ).

acidic metabolites $30 \mathrm{~min}$ after administration. On the other hand, the decrease in concentration was slower than for the other acidic metabolites. Therefore, the concentration of MA4 at $24 \mathrm{~h}$ after administration was higher than those of MA2 and MA3. In the female dogs, the time courses of the concentrations of the acidic metabolites were similar to those in the males. The decrease in the concentrations of MA2, MA3 and MA1 were about the same. The decrease in MA4 was slow.

As far as the basic metabolites were concerned, the concentration of MB7 was highest, followed by those of unchanged drug and MB5 up to $6 \mathrm{~h}$ after administration. 
TABLE V. Proportion of Radioactivity in Acidic and Neutral, Basic and Aqueous Metabolite Fractions of Urine and Bile after Oral Administration of $\left[{ }^{14} \mathrm{C}\right]$ Clentiazem to Male and Female Rats and Dogs

\begin{tabular}{|c|c|c|c|c|c|c|c|}
\hline \multirow{3}{*}{ Animal } & & \multicolumn{5}{|c|}{$\%$ of radioactivity } & \\
\hline & & \multicolumn{3}{|c|}{ Male } & \multicolumn{3}{|c|}{ Female } \\
\hline & & $\begin{array}{c}\text { Acidic and } \\
\text { neutral }\end{array}$ & Basic & Aqueous & $\begin{array}{l}\text { Acidic and } \\
\text { neutral }\end{array}$ & Basic & Aqueous \\
\hline \multirow[t]{2}{*}{ Rat } & Urine & $\begin{array}{l}11.7 \\
(1.4)\end{array}$ & $\begin{array}{l}29.6 \\
(3.6)\end{array}$ & $\begin{array}{l}58.7 \\
(7.2)\end{array}$ & $\begin{array}{l}34.3 \\
(8.6)\end{array}$ & $\begin{array}{l}32.9 \\
(8.3)\end{array}$ & $\begin{array}{l}32.8 \\
(8.3)\end{array}$ \\
\hline & Bile & $\begin{array}{c}33.5 \\
(21.2)\end{array}$ & $\begin{array}{c}3.2 \\
(2.0)\end{array}$ & $\begin{array}{c}63.8 \\
(40.2)\end{array}$ & $\begin{array}{l}12.1 \\
(2.9)\end{array}$ & $\begin{array}{c}4.5 \\
(1.1)\end{array}$ & $\begin{array}{c}83.4 \\
(19.4)\end{array}$ \\
\hline Dog & Urine & $\begin{array}{l}20.5 \\
(2.3)\end{array}$ & $\begin{array}{l}32.1 \\
(3.5)\end{array}$ & $\begin{array}{l}47.4 \\
(5.2)\end{array}$ & $\begin{array}{l}25.8 \\
(2.9)\end{array}$ & $\begin{array}{l}17.3 \\
(2.0)\end{array}$ & $\begin{array}{l}56.9 \\
(6.5)\end{array}$ \\
\hline
\end{tabular}

The value in parentheses are $\%$ of dose. Urinary data was obtained using pooled urine $(0-24 \mathrm{~h})$ of 8 male and 10 female rats, and 3 male and female dogs. Biliary data was obtained using pooled bile $(0-24 \mathrm{~h})$ of 5 rats.

The concentrations of MB1, MB2, MB3, MB4 and MB6 were low at every time of interval. The concentrations of MB7 and unchanged drug decreased rapidly in comparison with those of other basic metabolites falling below those of the other basic metabolites $24 \mathrm{~h}$ after administration. The concentration of MB6 increased gradually surpassing the unchanged drug and other basic metabolites.

Urinary and Fecal Excretion 1) Rat Table IV shows the excretion of radioactivity in urine and feces after oral administration of $\left[{ }^{14} \mathrm{C}\right]$ clentiazem to rats of both sexes.

The urinary excretion of radioactivity in male rats was about a half of that in females. These percentages were 14.9 and $34.4 \%$ of the dose in male and female rats $72 \mathrm{~h}$ after dosing, respectively. The excretion of radioactivity in the feces was higher in male rats than in females. These percentages were 79.1 and $63.1 \%$ of the dose in the male and female rats $72 \mathrm{~h}$ after dosing, respectively.

2) Dog The urinary excretion was 15.8 and $16.6 \%$ in the male and female dogs $72 \mathrm{~h}$ after dosing as shown in Table IV, respectively. Fecal excretion in the male and female dogs was 69.4 and $61.6 \%$, respectively. No significant sex differences were found in the urinary and fecal excretion.

Urinary Metabolites 1) Rat Table V shows the proportions of radioactivity in the acidic and neutral, basic and aqueous metabolite fractions, separated by extraction using $t$-BME from rat urine.

In the urine of male rats collected over the period of $0-24 \mathrm{~h}$ after dosing most radioactivity was accounted for in the aqueous metabolite fraction, followed by that in the basic metabolite fraction. The amount of radioactivity in the acidic and neutral metabolite fraction was small. In the urine of female rats, on the other hand, the radioactivity in the acidic and neutral, basic and aqueous metabolite fractions was about the same. The percentage of the dose in the acidic and neutral metabolite fraction in the male rats was extremely low, about one-sixth of that in the females. The percentage of the basic metabolite fraction in male rats was also low, about a half of that in females.

Table VI shows the proportions of acidic and basic metabolites in the urine of male and female rats. In the female rats, the most abundant urinary metabolite in the acidic and neutral metabolite fraction was MA4, followed by MA2. In contrast, male rats excreted only a only a small amount of acidic metabolites in the urine. MA4 was the main acidic metabolite.
TABLE VI. Percentages of Metabolites in Urine after Oral Administration of $\left[{ }^{14} \mathrm{C}\right]$ Clentiazem to Male and Female Rats

\begin{tabular}{ccc}
\hline & \multicolumn{2}{c}{ Concentration (\% of dose) } \\
\cline { 2 - 3 } Metabolite & Male & Female \\
\hline Clentiazem & 0.19 & 0.21 \\
MB1 & 0.54 & 1.95 \\
MB2 & 0.33 & 0.29 \\
MB3 & 0.46 & 0.80 \\
MB4 & 0.16 & 0.88 \\
MB5 & 0.74 & 0.47 \\
MB6 & 0.68 & 2.56 \\
MB7 & N.D. & N.D. \\
Others & 0.53 & 1.17 \\
Total & 3.63 & 8.33 \\
MA1 & 0.01 & 0.04 \\
MA2 & 0.03 & 2.24 \\
MA3 & 0.03 & 0.11 \\
MA4 & 0.13 & 5.29 \\
Others & 1.23 & 0.98 \\
Total & 1.43 & 8.66 \\
Grand total & 5.06 & 16.99 \\
\hline
\end{tabular}

Each value was obtained using pooled urine of 8 male and 10 female rats.

In male rats main the basic urinary metabolites were MB5, MB6 and MB1 and those in the females were MB6, MB1, MB4 and MB3.

2) Dog The percentage of radioactivity in the aqueous metabolite fraction was high, followed by those in the basic metabolite fraction and acidic and neutral metabolite fraction in male dogs, and in the acidic and neutral metabolite fraction, and basic metabolite fraction in female dogs as shown in Table V.

Table VII shows the percentages of each acidic and basic metabolite in the urine of male and female dogs. Although the percentage of the urinary acidic metabolites, with the exception of MA2, was somewhat higher in female dogs than in males, the difference was small. The main acidic urinary metabolites were MA2 and MA4 in the acidic and neutral metabolite fraction of both male and female dogs. The percentage of unchanged drug was about the same for both sexes. The percentages of MB7, MB5 and MB6 were higher in the male dogs than in the females. The percentages of MB1, MB3 and MB4 were low.

Biliary Excretion The percentages of radioactivity ex- 
TABle VII. Percentages of Metabolites in Urine after Oral Administration of $\left[{ }^{14} \mathrm{C}\right]$ Clentiazem to Male and Female Dogs

\begin{tabular}{ccc}
\hline & \multicolumn{2}{c}{ Concentration (\% of dose) } \\
\cline { 2 - 3 } Metabolite & Male & Female \\
\hline Clentiazem & 0.30 & 0.29 \\
MB1 & 0.05 & 0.04 \\
MB2 & 0.29 & 0.24 \\
MB3 & 0.17 & 0.12 \\
MB4 & 0.15 & 0.11 \\
MB5 & 0.87 & 0.39 \\
MB6 & 0.31 & 0.11 \\
MB7 & 0.98 & 0.56 \\
Others & 0.41 & 0.12 \\
Total & 3.53 & 1.98 \\
MA1 & 0.15 & 0.20 \\
MA2 & 0.66 & 0.75 \\
MA3 & 0.20 & 0.19 \\
MA4 & 0.34 & 0.43 \\
Others & 0.90 & 1.38 \\
Tota1 & 2.25 & 2.95 \\
Grand total & 5.78 & 4.93 \\
\hline
\end{tabular}

Each value was obtained using pooled urine of 3 dogs.

TABLE VIII. Percentages of Metabolites in Bile after Oral Administration of $\left[{ }^{14} \mathrm{C}\right]$ Clentiazem to Male and Female Rats

\begin{tabular}{ccc}
\hline & \multicolumn{2}{c}{ Concentration (\% of dose) } \\
\cline { 2 - 3 } Metabolite & Male & Female \\
\hline Clentiazem & 0.18 & 0.03 \\
MB1 & 0.21 & 0.15 \\
MB2 & 0.13 & 0.03 \\
MB3 & 0.08 & 0.04 \\
MB4 & 0.08 & 0.08 \\
MB5 & 0.35 & 0.14 \\
MB6 & 0.20 & 0.18 \\
MB7 & N.D. & N.D. \\
Others & 0.80 & 0.43 \\
Total & 2.03 & 1.08 \\
MA1 & 0.98 & 0.13 \\
MA2 & 1.46 & 0.25 \\
MA3 & 3.15 & 0.36 \\
MA4 & 5.35 & 0.43 \\
Others & 10.31 & 1.72 \\
Total & 21.25 & 2.89 \\
Grand total & 23.28 & 3.97 \\
\hline
\end{tabular}

Each value was obtained using pooled bile of 5 rats.

creted in the bile were 24.0 and $63.5 \%$ of the dose at 6 and $24 \mathrm{~h}$ after oral administration of $\left[{ }^{14} \mathrm{C}\right]$ clentiazem to male rats, respectively. On the other hand, the percentages of radioactivity in female rats were 7.0 and $23.8 \%$, respectively.

The proportions of radioactivity in the acidic and neutral, basic and aqueous metabolite fractions in the bile of male and female rats are shown in Table V. The proportion of radioactivity in the aqueous metabolite fraction was the highest in both male and female rats, followed by that in the acidic and neutral fraction. The proportion of radioactivity in the basic metabolite fraction was low in both sexes.

Biliary Metabolites Table VIII shows the percentages of the dose of acidic and basic metabolites in the bile of
TABLE IX. Proportion of Radioactivitity in Acidic, Basic Metabolites, Neutral and Aqueous Metabolite Fractions in Medium after Incubation of $\left[{ }^{14} \mathrm{C}\right]$ Clentiazem with the Liver Microsomes of Male and Female Rats

\begin{tabular}{crcc}
\hline \hline & \multicolumn{3}{c}{$\%$ of radioactivity in medium } \\
\cline { 2 - 4 } Metabolite & $\begin{array}{c}\text { Male rats } \\
(7 \mathrm{w} .)\end{array}$ & $\begin{array}{c}\text { Female rats } \\
(7 \mathrm{w} .)\end{array}$ & $\begin{array}{c}\text { Female rats } \\
(10 \mathrm{w} .)\end{array}$ \\
\hline MA1 & $2.39 \pm 0.45$ & $0.12 \pm 0.04$ & $0.14 \pm 0.04$ \\
MA2 & $0.38 \pm 0.04$ & $0.05 \pm 0.04$ & $0.05 \pm 0.03$ \\
MA3 & $5.01 \pm 2.78$ & $0.21 \pm 0.14$ & $0.11 \pm 0.03$ \\
MA4 & $0.40 \pm 0.24$ & $0.08 \pm 0.08$ & $0.04 \pm 0.02$ \\
Others & $0.38 \pm 0.38$ & $\mathrm{~N} . \mathrm{D}$. & $\mathrm{N} . \mathrm{D}$. \\
Clentiazem & $35.07 \pm 7.89$ & $65.44 \pm 13.53$ & $62.75 \pm 0.97$ \\
MB1 & $4.22 \pm 0.74$ & $15.28 \pm 7.27$ & $18.79 \pm 1.83$ \\
MB2 & $21.44 \pm 1.77$ & $6.68 \pm 4.83$ & $4.90 \pm 0.32$ \\
MB3 & $1.51 \pm 0.44$ & $0.56 \pm 0.49$ & $0.28 \pm 0.25$ \\
MB4 & $3.02 \pm 0.45$ & $1.52 \pm 0.69$ & $1.40 \pm 0.24$ \\
MB5 & $1.76 \pm 0.28$ & $0.59 \pm 0.37$ & $0.25 \pm 0.22$ \\
MB6 & $0.46 \pm 0.23$ & $\mathrm{~N} . \mathrm{D}$. & $\mathrm{N} . \mathrm{D}$. \\
MB7 & $3.51 \pm 0.06$ & $1.99 \pm 0.45$ & $1.38 \pm 0.15$ \\
Others & $2.71 \pm 2.27$ & $1.28 \pm 1.34$ & $3.95 \pm 2.91$ \\
Neutral metabolite fr. & $11.15 \pm 0.54$ & $3.14 \pm 0.74$ & $2.79 \pm 0.51$ \\
Aqueous metabolite fr. & $6.59 \pm 0.49$ & $3.06 \pm 0.50$ & $3.18 \pm 0.97$ \\
& & & \\
\hline
\end{tabular}

Each value represents the percent of radioactivity in the medium (mean \pm S.D. $n=3), \mathrm{N} . \mathrm{D} .=$ not detected. $\quad\left[{ }^{14} \mathrm{C}\right] \mathrm{Clentiazem}\left(10^{-5} \mathrm{M}\right)$ was incubated in $0.05 \mathrm{M} \mathrm{Na}$ $\mathrm{K}$ phosphate buffer containing rat liver microsomes (male ( 7 weeks old); $0.72 \mathrm{mg}$. protein $/ \mathrm{ml}$, female ( 7 weeks old); $0.46 \mathrm{mg}$ protein $/ \mathrm{ml}$, female ( 10 weeks old); $0.56 \mathrm{mg}$. protein/ml), glucose 6-phosphate (final concentration; $2.9 \mathrm{mM}$ ), glucose 6-phosphate dehydrogenase (10 units), NADP (concentration; $1.1 \mathrm{mM}$ ) and $\mathrm{MgCl}_{2} \cdot 6 \mathrm{H}_{2} \mathrm{O}$ (concentration; $14.3 \mathrm{~mm}$ ) at $37^{\circ} \mathrm{C}$ for $60 \mathrm{~min}$

male and female rats. In the acidic metabolites in the male rats, MA4 was most abundant, followed by MA3 and MA2 (not counting "others"). MA1 was minor. In the basic metabolites, the unchanged drug and the basic metabolites (MB1-6) could be detected but their concentrations were extremely low. The percentages of acidic metabolites were lower in female rats than in males, and similary the basic metabolites were somewhat lower in the female rat than in the males.

In Vitro Study The proportions of radioactivity of the acidic and basic metabolites, and those in neutral and aqueous metabolite fractions are shown in Table IX.

No significant difference was found in the proportions of radioactivity of acidic and basic metabolites and in neutral and aqueous metabolite fractions between 7 and 10 weeks old female rats. The percentages of acidic metabolites biotransformed by liver microsome were higher in male rats than in females. The amounts of basic metabolites were higher in male rats than in females. In the acidic metabolite fraction MA3 was most abundant, followed by MA1 in both male and female rats of 7 weeks old. In the 10 weeks old female rats, MA1 was abundant, followed by MA3. These values were $20-40$ times higher in male rats than in females. Although the percentages of MA2 and MA4 were low in both sexes, they were 5-10 times higher in male rats than in females. In the basic metabolite fraction, the percentage of clentiazem was higher in female rats than in males. The content of MB1 was about 4 times higher in female rats than in males. On the other hand, MB2 was about 3-4 times more abundant in male rats than in females. Other basic metabolites, MB3, MB4, MB5 and $\mathrm{MB}$, were 2-3 times more abundant in male rats compared with female. While MB6 was detected only in male rats. The proportions of neutral and aqueous metabolite 
fractions were higher in male rats than in females.

\section{Discussion}

The in vivo studies demonstrated clear sex-related differences in the disposition and metabolism of clentiazem in rats. Male rats, in comparison with females, showed decreased urinary excretion and increased biliary excretion of radioactivity, and higher plasma levels of radioactivity and lower urinary excretion of acidic metabolites.

Apparent sex-related differences in disposition, except for the time course of unchanged drug in plasma, might be largely the result of the differences in the amounts of acidic metabolites formed.

It may be that the acidic metabolites were formed as a consequence of a deamination (dealkylation) process by cytochrome P-450 or monoaminoxidase. ${ }^{11)}$ It has been reported that acidic metabolites of diltiazem were formed through biotransformation by microsomal cytochrome P-450. ${ }^{12)}$ Acidic metabolites from clentiazem might also be formed through biotransformation by cytochrome P-450 because of the structural similarity between both compounds. Thus, it is possible that the sex-related differences in activities and/or isozymes of cytochrome P-450 could cause differences in the metabolism of clentiazem. Differences in cytochrome P-450 isozymes between male and female rats are already known. ${ }^{13,14)}$

In an in vitro experiment using rat liver microsomes the formation of the $N$-monodemethylated basic metabolite (MB2) and acidic metabolites was high in male rats while the formation of deacetylated basic metabolite (MB1) was high in females. $N$-Demethylation and deamination could be distinguished by whether a methylene or methyl moiety, adjacent to the nitrogen atom of the dimethylaminoethyl moiety, was oxidized in the first step. Therefore, the sex-related differences in the deamination would be revealed by $N$-demethylation.

On the other hand, the deacetylating activity for clentiazem is somewhat higher in female rats since the proportion of deacetylated basic metabolite (MB1) was higher in females than in males.

In vitro experiments using rat hepatocytes showed a more rapid deacetylation of diltiazem in female rats than in males. ${ }^{15)}$ Therefore, it is possible that clentiazem might also be biotransformed more rapidly in female rats than in males because of the structural similarity. However, the plasma levels of MA1 and MA3 decreased slowly in both sexes while those of MA2 (deacetylated MA1) and MA4 (deacetylated MA3) increased rapidly, especially in the male, despite the higher deacetylation activity in the females. The extent of the increase in MA2 and MA4 exceeded that of the decrease in MA1 and MA3. It may be that the formation of the deacetylated acidic metabolites (MA2 and MA4) from the corresponding basic metabolites, such as MB1, MB3, MB4 or MB6, led to preferential biotransformation compared with the formation from MA1 and MA3.

Most of the radioactivity after oral administration of $\left[{ }^{14} \mathrm{C}\right]$ clentiazem to rats was excreted in the feces through biliary elimination. In spite of the higher plasma level of acidic metabolites in males, their urinary level was about one forth that found in females. A similar observation was reported for the disposition and metabolism of nilvadipine in the rat. ${ }^{16)}$ It has been suggested that an active renal secretory mechaism in female rats might affect the urinary excretion of the carboxyl metabolites of nilvadipine.

We also studied the urinary and fecal excretion, the time courses of radioactivity and unchanged drug in plasma and the proportion of metabolites in urine and plasma after oral administration of $\left[{ }^{14} \mathrm{C}\right]$ clentiazem to male and female dogs.

No difference in the urinary excretion of radioactivity (about 15\%) between male and female dogs was found. Moreover, no sex difference in fecal excretion was found. Therefore, there appears to be no sex difference in the excretion pattern in dogs after oral administration of clentiazem. Furthermore, no sex difference was found in the plasma concentration of unchanged drug. No significant sex differences were found in the dogs in the pharmacokinetic parameters of the unchanged drug.

In the dog the plasma metabolite, $O$-demethylated clentiazem (MB7) was abundant, followed by the unchanged drug in both sexes. Little acidic metabolite was found. No sex difference in the percentages of urinary metabolites in dogs was found. The main metabolites in dog urine were MB7, $O$-demethyl- $N$-monodemethyl clentiazem (MB5) and the acidic metabolite MA2. The main plasma metabolite was an acidic one in male rats. The main plasma metabolite was deacetyl clentiazem (MB1) in female rats. The main urinary metabolites in male and female rats were MB5, deacetyl- $O$-demethyl- $N$-monodemethyl clentiazem (MB6) and MB1. However, the proportion of the urinary acidic and neutral metabolite fraction in the male rat was lower than in the female. Thus, it was thought that there was a sex difference in the renal clearance of acidic metabolites. None of these difference was found between male and female dogs.

Furthermore, the metabolism between rat and dogs was different. The major metabolic pathways were deamination and deacetylation in rats, and $O$-demethylation in dogs.

In conclusion, clear sex-related differences were found in rats. The cause of these differences may be due to quantitative differences in the formation of acidic metabolites, for basic metabolites differences in cytochrome P-450, the differences in the renal clearance of acidic metabolites. No sex-related difference was found in dogs. There was also a species difference between rat and dog.

Acknowledgements The authors wish to thank Miss N. Suzuki for her technical assistance.

\section{References}

1) H. Inoue, M. Konda, T. Hashiya, H. Ohtsuka, K. Takahashi, M. Gaino, T. Date, K. Aoe, M. Takeda, S. Murata, H. Narita, and T. Nagao, J. Med. Chem., 34, 675 (1991).

2) M. M. Chaffman and R. N. Brogden, Drugs, 29, 387 (1989).

3) Y. Sugawara, M. Ohashi, S. Nakamura, S. Usuki, T. Suzuki, Y. Ito, T. Kume, S. Harigaya, A. Nakao, M. Gaino, and H. Inoue, $J$. Pharmacobio-Dyn., 11, 211 (1988).

4) Y. Sugawara, S. Nakamura, S. Usuki, Y. Ito, T. Suzuki, M. Ohashi, and S. Harigaya, J. Pharmacobio-Dyn., 11, 224 (1988).

5) T. Meshi, J. Sugihara, and Y. Sato, Chem. Pharm. Bull., 19, 1546 (1971).

6) J. Sugihara, Y. Sugawara, H. Ando, S. Harigaya, A. Etoh, and K. Kohno, J. Pharmacobio-Dyn., 7, 24 (1984).

7) V. Rovei, R. Gomeni, M. Mitchard, J. Larribaud, Ch. Blatix, J. J. Theboult, and P. L. Morselli, Acta Cardiologica, 35, 35 (1980).

8) P. L. Morselli, V. Rovei, M. Mitchard, A. Durand, R. Gomeni, and J. Larribaud, Pharmacokinetics and metabolism in man. "New Drug Therapy with a Calcium Antagonist," ed. by R. J. Bing, Excepta 
Medica, Amsterdam and Princeton, 1979, p. 152.

9) S. Nakamura, Y. Sugawara, T. Fukushima, Y. Ito, M. Ohashi, and O. Takaiti, Biol. Pharm. Bull., 16, 635 (1993).

10) S. Nakamura, M. Ohashi, T. Suzuki, Y. Sugawara, S. Usuki, and O. Takaiti, Arzneim.-Forsch., 39, 1100 (1989).

11) M. Hirobe, T. Kamataki, "Drug Metabolism," Vol. 18, ed. by I. Suzuki, H. Tanaka, H. Yajima, H. Fukuda, H. Sezaki, K. Koga, M. Hirobe, and T. Nakajima, Hirokawa Publishing Company, Tokyo, 1990, pp. 35-47.

12) S. Nakamura, Y. Ito, T. Fukushima, Y. Sugawara, and M. Ohashi, J. Pharmacobio-Dyn., 13, 612 (1990).
13) T. Kamataki, K. Maeda, Y. Yamazoe, T. Nagai, and R. Kato, Biochem. Biophys. Res. Commun., 103, 1 (1981).

14) T. Kamataki, K. Maeda, Y. Yamazoe, T. Nagai, and R. Kato, Arch. Biochem. Biophys., 225, 758 (1983).

15) J. P. Theno, A. Durand, and G. Gillet, Sex difference in the biotransformation of diltiazem, 1988, in vitro study with rat hepatocytes. IInd International ISSX Meeting, ISSX-88, "Xenobiotic metabolism and disposition" in Kobe (1988).

16) S. Terasita, Y. Tokuma, and M. Sekiguchi, Xenobiotica, 19, 1221 (1989). 